\title{
RELIGĨ̃o E POLÍTICA NA EDUCAÇÃO: NOTAS SOBRE A REDE CATÓLICA NO TERRITÓRIO MARANHENSE ${ }^{1}$
}

\author{
RELIGION AND POLICY IN EDUCATION: NOTES ON THE CATHOLIC \\ NETWORK IN MARANHENSE TERRITORY
}

REDE EDUCATIVA CATÓLICA NO MARANHÃO

\section{CATHOLIC EDUCATION NETWORK IN MARANHÃO}

\author{
CUSTÓDIO, Maria Aparecida Corrêa ${ }^{2}$ \\ SOUSA, Mariana de Paula Medeiros de ${ }^{3}$
}

\begin{abstract}
Resumo
Este artigo aborda os trabalhos educacionais da Ordem dos Frades Menores Capuchinhos e da Congregação das Irmãs Missionárias Capuchinhas, no Maranhão republicano, na perspectiva de suplência diante do quadro de analfabetismo encontrado em várias regiões desse estado. Conjectura-se que, apesar da pretensa laicização do Estado brasileiro, esse grupo religioso fez uso de muitos espaços para se expandir e estruturar suas obras, inclusive, com certo apoio do próprio Estado que, por sua vez, beneficiou-se com esses serviços.
\end{abstract}

Palavras-chave: História da educação, catolicismo, contexto político.

\begin{abstract}
This article deals with the educational works of the Order of Friars Minor Capuchin and the Congregation of Sisters Missionary Capuchin, in the Republican Maranhao State, in the perspective of compensation on the matter of illiteracy found in various regions of that state.
\end{abstract}

\footnotetext{
${ }^{1}$ Este estudo resulta de pesquisas sobre "Congregações femininas nativas e processos de expansão nos estados brasileiros", vinculadas ao Projeto Temático "Congregações Católicas, Educação e Estado Nacional no Brasil", abrigado pelo Grupo Focus (FeUnicamp) e financiado pela Fapesp (2012-2017). Uma versão parcial foi apresentada no IX Congresso Brasileiro de História da Educação (2017), com apoio da Fapema.

${ }^{2}$ Doutora em Educação pela Universidade de São Paulo - USP. Professora adjunta no Curso de Pedagogia da Universidade Federal do Maranhão, campus Imperatriz. E-mail: <mapcocustodio@yahoo.com.br>.

${ }^{3}$ Acadêmica de Comunicação Social da Universidade Federal do Maranhão, campus Imperatriz. Bolsista de iniciação científica. E-mail: <marianadepaulamds@gmail.com>.
} 
It conjectures that, despite the alleged laicization of the Brazilian State, this religious group made use of many spaces to expand and structure its works, including some support from the State itself, which in turn benefited from these services.

Keywords: History of education, catholicism, political context.

\section{Introdução}

No Brasil, a Igreja Católica suprimiu muitas lacunas no campo da educação escolar, pois, desde o Império, o governo central transferia para as províncias a responsabilidade pela escolarização básica da população, deixando um quadro de analfabetismo que se prolongou no período republicano e até hoje não foi resolvido de forma satisfatória, como bem evidenciam os indicadores sociais do Instituto Brasileiro de Geografia e Estatística (IBGE, 2015). ${ }^{4}$ Do ponto de vista da Igreja, especialmente nos primórdios da República, sua hierarquia estava preocupada com a formação de quadros católicos e disposta a defender enfaticamente a escola privada e confessional, e o ensino religioso (RORIZ, 1951), uma vez que se fortalecia com a chegada de congregações europeias desde o final do século XIX (LEONARDI, 2010; QUEIROZ, 2016) e com a criação de congregações brasileiras nos territórios de missão de padres estrangeiros (CUSTÓDIO, 2014a; CUSTÓDIO 2014b), grande parcela delas voltada para a docência. Durante boa parte do século XX, muitas congregações dedicaram-se principalmente à criação de colégios secundários para as elites e classes médias brasileiras; algumas implantaram escolas populares em áreas interioranas e rurais, fortalecendo grupos étnicos e classes populares; outras se ocuparam com escolas normais e universidades, sabendo que seus serviços eram de grande utilidade social para o país, diante das imensas brechas deixadas pelo Estado no setor educacional. Paradoxalmente, em um contexto de pretensa laicização do Estado brasileiro5, mas de certa forma apoiados por ele, esses grupos religiosos, ao exercerem a suplência, fizeram uso de muitos espaços para se expandir e capitalizar recursos e prestígio social. O Estado, por sua vez, beneficiou-se com

\footnotetext{
${ }^{4}$ De 2004 a 2014, embora tenha havido queda da taxa de analfabetismo em todas as faixas etárias, entre a população mais velha a porcentagem daqueles que não sabem ler nem escrever é ainda significativa (13,8\% entre pessoas de 55 a 64 anos; $26,4 \%$ de 65 anos ou mais) e mesmo entre os indivíduos de 15 anos ou mais $(8,3 \%)$.

${ }^{5} \mathrm{Na}$ mesma acepção de Cunha (2010, p. 187, grifo do autor): a laicidade "[...] é um processo. Ou seja: qualquer definição de Estado laico será sempre aproximativa, pois ele é uma construção histórica, como, aliás, o conceito de democracia. Em primeira aproximação, a liberdade de crença e de culto é o primeiro estágio da laicidade; o fim de uma religião oficial, o segundo; a separação entre o Estado e as confissões religiosas, o terceiro; etc."
} 
esses trabalhos, uma vez que precisava combater o analfabetismo e atender às demandas educacionais da população.

O presente artigo pretende analisar esses processos a partir de indícios observados na documentação da Ordem dos Frades Menores Capuchinhos e da Congregação das Irmãs Missionárias Capuchinhas, a respeito de sua missão socioeducativa no estado do Maranhão, imbricados com vestígios apreendidos nas fontes jurídicas extrínsecas à organização religiosa. Trata-se de um relevante campo de investigação para a construção de uma história da educação brasileira de base regional, nos mesmos termos de Carlo Ginzburg (1972) ao se referir à história religiosa da Itália. Segundo esse autor, enquanto não se dispor de pesquisas sobre cultos e devoções locais, estruturas das dioceses e das paróquias, "uma história religiosa italiana sobre base regional - consequentemente, uma história religiosa tout court - será impossível” (GINZBURG, 1972, p. 10). Parafraseando Ginzburg, pode-se conjecturar que, enquanto não se dispor de pesquisas regionais sobre história de instituições, práticas educativas, sujeitos históricos, cultura material e muitos outros eixos, uma história da educação brasileira propriamente dita ficará sempre incompleta.

\section{O campo de missão}

Com base no clássico estudo de Nagle (2006), pode-se compreender que a construção republicana de uma educação nacional foi mais no sentido ideológico do que efetivo. Recorrendo a outros estudos, percebe-se também que o debate sobre a educação brasileira se acirrou quando os movimentos sociais reivindicaram a ampliação do atendimento escolar no contexto de industrialização/urbanização, que trazia a demanda da escolarização (HILSDORF, 2005). ${ }^{6}$ Havia urgência de alfabetizar a população que, em sua maioria, era analfabeta e excluída da cidadania (como o direito de votar). Por esse motivo, a procura por soluções nesse período foi mais voltada para a base da educação, ou seja, a escola primária principalmente porque os muitos problemas sociais que o país enfrentava foram atribuídos à falta de educação do povo.

\footnotetext{
${ }^{6}$ Em 1932, o grupo dos pioneiros da Escola Nova captou esse anseio popular e lançou um manifesto ao povo e ao governo, mais conhecido como Manifesto dos Pioneiros da Educação Nova. Esse manifesto sinaliza a tomada de consciência da educação como um problema nacional, faz um diagnóstico e indica rumos para modernizá-la a partir das descobertas científicas do momento e da implantação das pedagogias contemporâneas advindas do Movimento da Escola Nova (AZANHA, 2006). A Constituição de 1934 absorve parte do conteúdo desse manifesto e dedica um capítulo para a Educação, garantindo princípios educacionais relevantes, entre os quais gratuidade e obrigatoriedade do ensino primário. Contudo, no contexto autoritário do Estado Novo, grande parte dessa prescrição foi deixada de lado na Constituição de 1937 (SAVIANI, 2011).
} 
Outra marca desse período foi a criação de grupos escolares, 7 centrando força na modernização da instrução pública, como desejava o Movimento da Escola Nova, e na universalização da educação primária; todavia, sua implantação no Brasil ocorreu em diversos momentos da Primeira República. No Maranhão, foco deste ensaio, políticos e intelectuais, influenciados pelo fervor ideológico adquirido no início da República e inspirados nos grupos escolares de São Paulo, mobilizaram-se para implantar esse tipo de escola. Os primeiros grupos escolares foram criados em 1903, na capital, São Luís (para isso, seis escolas estaduais foram redimensionadas em dois grupos); no interior, os grupos começaram a surgir em 1906, nos municípios de Rosário e São Bento, e, em 1908, em Codó.

Devido a uma série de fatores, que vão desde a insuficiência de recursos financeiros até a falta de professores qualificados, os grupos escolares maranhenses foram extintos em 1912 e reerguidos em 1919. Mas somente a partir de 1920 o governo estadual construiu prédios próprios para esses grupos. Tais instabilidade e precariedade levam Silva (2015) a concluir que, de 1903 a 1920, os grupos escolares do Maranhão funcionaram muito mais na imaginação das pessoas que os idealizavam do que na prática; mesmo assim contribuíram para expandir a importância do ensino primário, mobilizar reformas educacionais e diminuir o analfabetismo. Pode-se concordar com a autora, pois, na Primeira República, segundo as coleções de leis e decretos examinadas, prescreve-se mais a criação de escolas mistas, escolas para sexos distintos (sobretudo masculino) e escolas rurais. É notável observar que somente a Lei n. 815/1918 chegou a prescrever a criação de 34 escolas em variados povoados, apontando perspectiva de investimento educacional no interior do Maranhão (cf. Quadro 1). Escolas de níveis mais avançados, como os grupos escolares, que exigiam infraestrutura física e pedagógica e, consequentemente, maiores recursos humanos e financeiros, são pouco mencionadas na legislação investigada; a prescrição para a criação de grupos escolares ocorre mais em períodos posteriores.

Quadro 1. Prescrição para criação de escolas no Estado do Maranhão em 1918.

\begin{tabular}{l|l} 
Tipo de escola & Lugar \\
\hline
\end{tabular}

\footnotetext{
${ }^{7}$ Os grupos escolares ofereciam um ensino graduado e seriado e fundamentavam-se na classificação dos alunos por níveis de conhecimento, agrupados em classes com um professor. Eles são expressão também das preocupações higienistas da época e das exigências do método intuitivo, em voga na educação mundial desde o final do sec. XIX (a ideia básica era de que a criança aprendia pelos sentidos, o que exigia espaços, materiais e procedimentos adequados).
} 


\begin{tabular}{|l|l|}
\hline 16 escolas do sexo masculino & Povoado Curral da Igreja, no termo do Arary, Comarca de \\
& Victoria do Mearim \\
Vila de Pastos Bons \\
Vila de São José dos Matões \\
Povoado de Mocambo, município de Rosário \\
Povoado de Santa Cruz, município de Miritiba \\
& Povoado da Mata, município de Codó \\
& Povoado de Inhaúma, município de Caxias \\
& Povoado de Trizidella, município de Pedreiras \\
& Povoado de Gama, município de Pinheiro \\
& Povoado de Paraty, município de Guimarães \\
& Povoado de Itacolomy, 3 Distrito do Bacanga \\
& Povoação de Pery de Baixo, município de Rosário \\
& Santo Antônio e Almas \\
& Vila de Icatú \\
& Povoado de Ponte, município de Caxias \\
Vila de Imperatriz
\end{tabular}

Fonte: MARANHÃO, 1918.

A partir de uma ótica mais crítica, nas entrelinhas desses dados pode-se vislumbrar a opção política por escolas menos onerosas para o Estado. Na análise de Cruz (2013), os governadores das três primeiras décadas do século XX tinham uma visão diversa de economia dos recursos públicos para expansão da escola primária graduada, cujo modelo de ensino se disseminava por meio dos grupos escolares. Eles alegavam sempre a carência de recursos, mas o problema "se localizava na precária capacidade de gerenciar tais recursos, que durante o século XIX e até a metade do século XX, praticamente não foram empregues no patrimônio público" (CRUZ, 2013, p. 3). Todavia, pode-se reconhecer que a criação de escolas mistas, 
masculinas e rurais era necessária para superar o alto índice de analfabetismo que assolava não somente o Maranhão, mas todo o país, como indicam os estudos de Nagle (2006), sobre a educação brasileira na Primeira República, e de Silva (2015), a respeito dos grupos escolares maranhenses.

A questão torna-se mais complexa quando se pensa nas tardias iniciativas educacionais de alguns governos municipais maranhenses, justificadas pela histórica problemática das receitas irrisórias das prefeituras brasileiras. Em Imperatriz, que iria se constituir como a segunda cidade mais populosa do Maranhão e atual polo comercial e universitário, apenas em 1935 foi criada a primeira escola municipal (Decreto Municipal n. 2/1935) e, em 1936, a segunda (Decreto Municipal n. 10/1936), no antigo distrito de Montes Altos, hoje município de pequeno porte. Essas iniciativas foram tomadas após as repetidas recomendações do governador para se atender à demanda de um grande número de crianças em idade escolar sem escola, além da necessidade de proteger a infância, combater o analfabetismo e fazer os "poderes públicos não descuidarem na criação de escolas nos centros populosos" (Decreto Municipal n. 10/1936). No entanto, na mesma Imperatriz, a prescrição para criação de escolas municipais, sobretudo rurais, é mais frequente entre 1950 e 1957. Mesmo assim, a incipiência é notória: criavam-se escolas ambulantes, instaladas onde fosse julgado necessário, podendo ser deslocadas a qualquer momento, pois funcionavam com tempo determinado; contratavam-se professoras leigas (cf. Quadro 2). ${ }^{8}$

Quadro 2. Criação de escolas municipais em Imperatriz entre 1950 e 1959.

\begin{tabular}{|l|l|l|}
\hline LEGISLAÇÃO & \multicolumn{1}{|c|}{ PRESCRIÇÃO } & \multicolumn{1}{|c|}{ PREFEITO } \\
\hline Lei n. 27/1950 & Cria uma escola municipal e respectivo cargo de professora. & $\begin{array}{l}\text { Simplício Alves } \\
\text { Moreira }\end{array}$ \\
\hline Lei n. 35/1951 & $\begin{array}{l}\text { Doa ao Estado do Maranhão um terreno pertencente ao } \\
\text { patrimônio do município, com uma área de } 10.000 \mathrm{~m}^{2} \text {, situado } \\
\text { no povoado Clementino, para nele ser construído um prédio }\end{array}$ & $\begin{array}{l}\text { Urbano Rocha Miranda } \\
\text { Roca }\end{array}$ \\
\hline
\end{tabular}

8 Em geral, os livros de transcrição de portarias e decretos da Prefeitura de Imperatriz tratam de impostos, nomeação e atribuição de agentes fiscais; balancetes, orçamentos anuais e alterações do orçamento no decorrer do ano; nomeações e outros assuntos referentes aos servidores municipais, especialmente, da Guarda Municipal e do Juizado de Direito. Abordam ainda regulamentação do comércio, agricultura e prescrições para a vida social, como proibir moradores de deixar cabras, ovelhas e outros animais soltos pelas ruas. Contêm também ofícios dirigidos às autoridades estaduais, seja para comunicar ou esclarecer alguma coisa, seja para expor problemas, solicitar soluções ou apresentar propostas. Entre esses temas, podem ser garimpados vários assuntos relativos à educação. No entanto, o desafio é localizar a documentação do período 1937-1949, a fim de se ter uma visão mais abrangente da educação e da própria história da cidade e de seus distritos (a maioria, emancipado para município na atualidade). 


\begin{tabular}{|c|c|c|}
\hline & destinado a uma escola rural. & \\
\hline Lei n. 12/1953 & $\begin{array}{l}\text { Doa ao Estado do Maranhão um terreno pertencente ao } \\
\text { patrimônio do município, com uma área de } 10.000 \mathrm{~m}^{2} \text {, situado } \\
\text { no Gameleira, para nele ser construído um prédio destinado a } \\
\text { uma escola rural. }\end{array}$ & $\begin{array}{l}\text { Simplício Alves } \\
\text { Moreira }\end{array}$ \\
\hline Lei n. 58/1955 & $\begin{array}{l}\text { Cria a Escola Simplício Moreira (rural), no povoado Boca da } \\
\text { Mata e respectivo cargo de professora com salário de } 400 \\
\text { cruzeiros. }\end{array}$ & $\begin{array}{l}\text { Simplício Alves } \\
\text { Moreira }\end{array}$ \\
\hline Lei n. 66/1955 & $\begin{array}{l}\text { Cria uma escola rural no povoado Bebedouro, denominada } \\
\text { Escola Humberto de Campos. }\end{array}$ & $\begin{array}{l}\text { Simplício Alves } \\
\text { Moreira }\end{array}$ \\
\hline Lei n. 67/1955 & $\begin{array}{l}\text { Cria uma escola rural no povoado Olho D'água, denominada } \\
\text { Escola Professor Nascimento de Moraes. Foi criado também } \\
\text { mais um cargo para professor com salário de } 400 \text { cruzeiros. }\end{array}$ & $\begin{array}{l}\text { Simplício Alves } \\
\text { Moreira }\end{array}$ \\
\hline Lei n. 68/1955 & $\begin{array}{l}\text { Cria uma escola rural no povoado Varjão, denominada Escola } \\
\text { Coelho Neto. Foi criado mais um cargo para professora com } \\
\text { salário de } 400 \text { cruzeiros mensais. }\end{array}$ & $\begin{array}{l}\text { Simplício Alves } \\
\text { Moreira }\end{array}$ \\
\hline Lei n. 75/1956 & $\begin{array}{l}\text { Cria uma escola rural em Alto Bonito, denominada Escola } \\
\text { Djalma Brito. }\end{array}$ & $\begin{array}{l}\text { Antenor } \\
\text { Fontenele } \\
\text { Bastos }\end{array}$ \\
\hline Lei n. 90/1957 & $\begin{array}{l}\text { Cria uma escola rural em São Raimundo Nonato, denominada } \\
\text { Escola Pena Rodrigues. Foi criado mais um cargo para } \\
\text { "professora leiga" com salário de } 400 \text { cruzeiros mensais. }\end{array}$ & $\begin{array}{l}\text { Raimundo de } \\
\text { Moraes Barros }\end{array}$ \\
\hline Lei n. 109/1957 & $\begin{array}{l}\text { Cria uma escola municipal em Tanque, denominada Escola } \\
\text { Professor Sousa Lima. }\end{array}$ & $\begin{array}{l}\text { Antenor } \\
\text { Fontenele } \\
\text { Bastos }\end{array}$ \\
\hline Lei n. 110/1957 & $\begin{array}{l}\text { Cria uma escola municipal no povoado Capim de Cheiro com a } \\
\text { denominação Divina Providência. }\end{array}$ & $\begin{array}{l}\text { Antenor } \\
\text { Fontenele } \\
\text { Bastos }\end{array}$ \\
\hline Lei n. 111/1957 & Cria mais cinco escolas municipais "ambulantes". & $\begin{array}{l}\text { Antenor } \\
\text { Fontenele } \\
\text { Bastos }\end{array}$ \\
\hline Lei n. $129 / 1959$ & $\begin{array}{l}\text { Cria uma verba especial de } 60 \text { mil cruzeiros para a construção } \\
\text { do prédio da escola na Vila Simplício Moreira. }\end{array}$ & $\begin{array}{l}\text { Raimundo de } \\
\text { Moraes Barros }\end{array}$ \\
\hline Lei n. 130/1959 & $\begin{array}{l}\text { Dispõe sobre apropriação de imóveis e doação de um terreno } \\
\text { municipal para nele ser edificado o prédio da Escola Técnica } \\
\text { Profissional. }\end{array}$ & $\begin{array}{l}\text { Raimundo de } \\
\text { Moraes Barros }\end{array}$ \\
\hline
\end{tabular}

Fonte: IMPERATRIZ, 1950-1959.

Certamente, a política educacional de Imperatriz nos anos 1950 estava na trilha da política nacional de expansão do ensino primário e combate ao analfabetismo, apregoada na gestão do presidente Eurico Gaspar Dutra (1946-1951), que almejava atingir, sobretudo, os interiores do Brasil; e no bojo das campanhas nacionais de Alfabetização de Adultos (1947) e Educação Rural (1952). Por conta desse programa federal, o período de 1946 a 1949 marcou o início da "fase mais significativa de expansão da escola primária vivenciada até então, na história do Maranhão", sendo o estado "contemplado com recursos para construção de 112 prédios escolares para funcionamento de escolas rurais [...] 26 prédios para implantação de 
grupos escolares nas sedes de alguns municípios" (CRUZ, 2013, p. 12). Foi então que Imperatriz implantou seu primeiro grupo escolar, a escola Governador Archer, em 1951 (na atualidade é um estabelecimento de ensino médio). Acrescente-se que, nas décadas de $1960 \mathrm{e}$ 1970, Imperatriz foi favorecida pelo Projeto "Capelas-Escolas", desenvolvido pelo capuchinho Osvaldo Coronini quando exercia a função de inspetor do ensino primário do município, e viveu um momento fecundo de expansão de escolas em diversos povoados, especialmente nas áreas rurais (CUSTÓDIO; CARDOSO, 2017).

\section{Circuito missionário e auxílio do Estado}

Diante do quadro deficitário do sistema público de ensino, como se viu na região de Imperatriz e mesmo em todo o estado do Maranhão, não é difícil entender a grande relevância das instituições católicas. Com certeza, por essa razão, o circuito missionário de frades e freiras capuchinhos priorizou a fundação de paróquias e casas religiosas, e nelas escolas primárias e outros serviços socioeducativos, nas variadas cidades do interior e periferias da capital maranhense, de acordo com sua historiografia (NEMBRO, 1957; CONGREGAÇÃO DAS IRMÃS MISSIONÁRIAS CAPUCHINHAS, 1976; CASTILHO, 2004). Como já conjecturado em outro ensaio (CUSTÓDIO, 2015), pode-se supor que a perspectiva inicial desses missionários era superar o analfabetismo, pois os padres criaram diversas escolas paroquiais e as irmãs dirigiram ou implantaram escolas que começavam com o nível primário, uma vez que se preocupavam em demasia com o fato de a população não saber ler nem escrever, o que se constituía em um sério empecilho para a evangelização.

Figura 1. Escola capuchinha em Barra do Corda (MA) - s.d., c. séc. XX. 


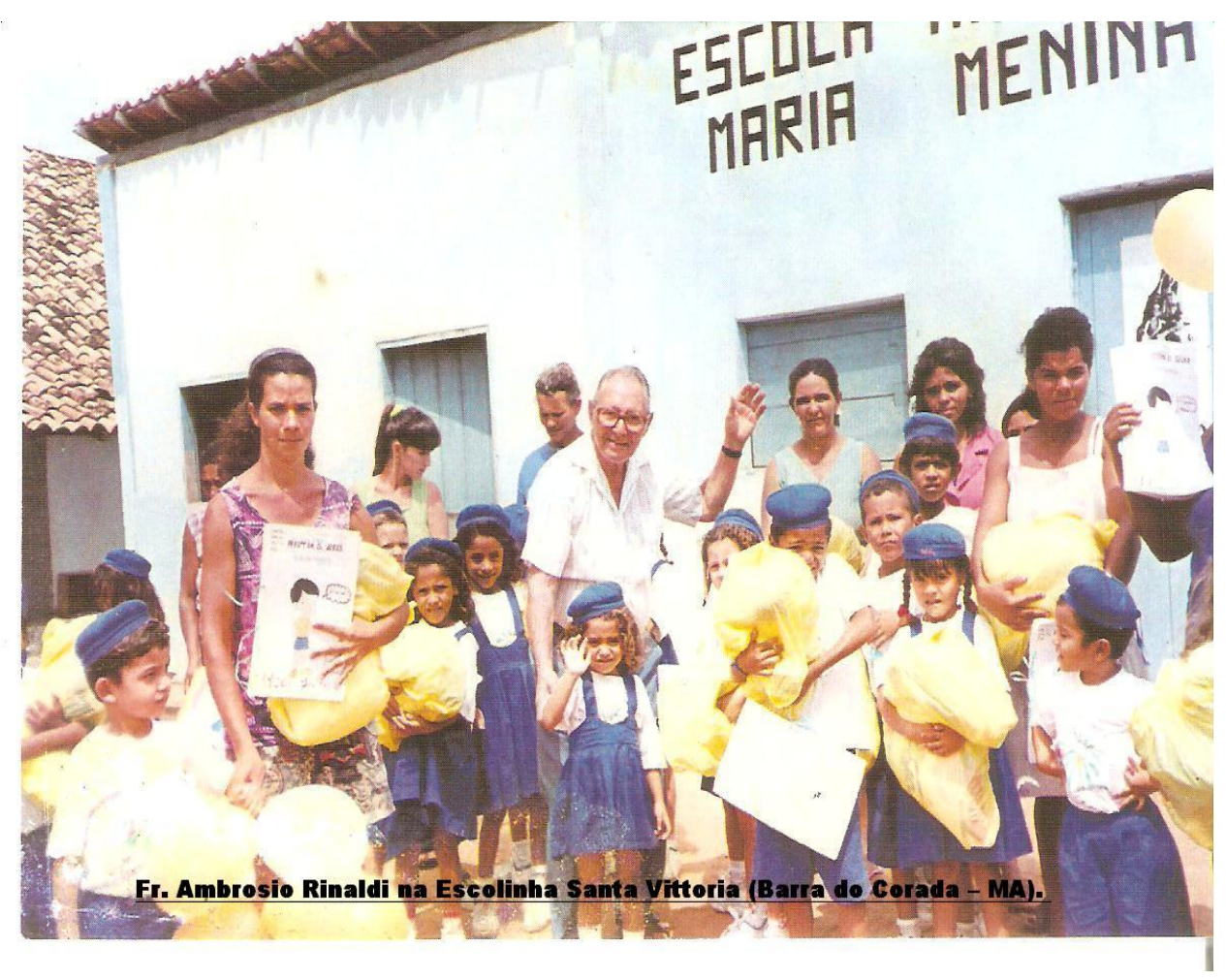

Fonte: Arquivo Histórico da Província Nossa Senhora do Carmo (São Luís - MA).

Como indicam a historiografia citada e a iconografia selecionada (cf. Figuras 1 e 2), com o tempo, esses religiosos constituíram uma rede de instituições educativas bem estruturadas como grupos escolares, ginásios, cursos secundários e profissionalizantes, escolas normais - os frades trataram de criar logo a Associação Educadora Italo-Brasiliense, mantenedora de todos os trabalhos (ASSOCIAÇÃO EDUCADORA ITALO-BRASILIENSE, 1912). Há de se inquirir como teriam conseguido manter e ampliar seus empreendimentos apesar dos parcos recursos que angariavam de seus fiéis paroquianos e das famílias dos estudantes, conforme se observa nos relatórios do movimento religioso e financeiro das paróquias depositados no Arquivo Histórico da Província Nossa Senhora do Carmo (AHPNSC), em São Luís do Maranhão.

Figura 2. Escola capuchinha em Presidente Dutra (MA) - 1960. 


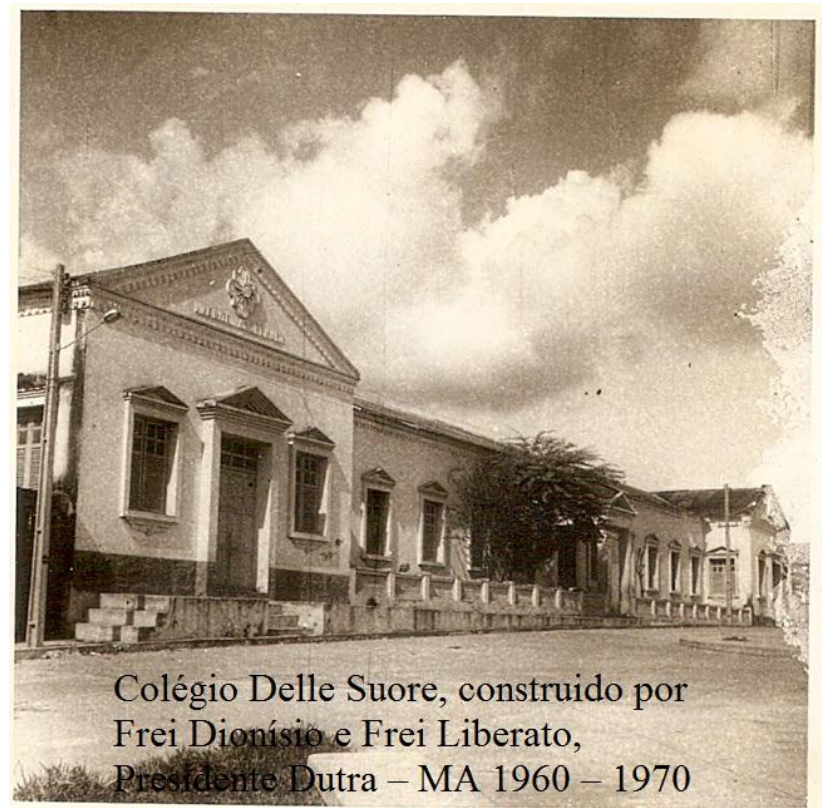

Fonte: Arquivo Histórico da Província Nossa Senhora do Carmo (São Luís - MA). 9

No tocante aos padres, parte da base de sustentação de seus trabalhos provinha muitas vezes de campanhas realizadas entre parentes, amigos e antigos paroquianos da longínqua Itália. Frei Osvaldo Coronini, citado anteriormente, tem uma vasta correspondência que comprova essa prática, mas não foi o único capuchinho italiano a fazer uso desse recurso (cf. AHPNSC). No caso das freiras - e não devia ser diferente com os frades - parece que era de praxe elas se articularem com políticos locais e regionais, cujos nomes aparecem aqui e acolá em sua historiografia (SILVA; CASTRO, 2004; REVISTA DO CENTENÁRIO DAS IRMÃS MISSIONÁRIAS CAPUCHINHAS, 2004), possivelmente para montar redes de sociabilidade com pessoas influentes que transitavam por vários setores da sociedade e podiam ajudá-las a avançar em seus empreendimentos educacionais. Também as elites de seus colégios - com muitos membros envolvidos na política - apoiavam e prestigiavam o trabalho delas, principalmente por causa da educação de seus filhos, mas também porque, tendo sido educados pelas irmãs, conseguiram conquistar posições mais altas.

Fossem padres, fossem freiras, parte da sustentação de suas instituições era bancada pelo próprio Estado, seja na forma de subvenção, seja como pagamento do corpo docente que trabalhava nas escolas capuchinhas, ou ainda na forma de outros tipos de benefícios. Essa espécie de investimento nas empresas católicas chama muito a atenção, pois, na fase

\footnotetext{
${ }^{9}$ A legenda diz que essa escola foi construída pelos capuchinhos italianos Dionísio e Liberato. Trata-se do novo prédio para a escola que fora criada em 1948 pela Congregação das Irmãs Missionárias Capuchinhas, em Presidente Dutra (MA), denominada Educandário São Francisco de Assis. Mas foi extinta em 1977.
} 
primordial da República, a separação entre Estado e Igreja foi assumida de maneira muito incisiva no Maranhão: um dos primeiros atos do governo provisório, presidido por Pedro Augusto Tavares Júnior, foi a promulgação do Decreto n. 7/1889, que estabelecia a liberdade de culto no Estado e a suspensão do pagamento de quaisquer subsídios à Igreja Católica.

Entretanto, o Governo Provisório da República, ainda instável e temendo por certo a grande influência e prestígio da Igreja, haja vista que praticamente toda a população nacional era de católicos, ainda não se decidira a tanto. Consequentemente, o Ministro da Justiça apressou-se em telegrafar recomendando a anulação do prematuro decreto; e porque não o fizesse nosso governante, o próprio Marechal Deodoro telegrafou ao então TenenteCoronel João Luís Tavares, Comandante da Guarnição Federal, determinando que declarasse sua nulidade. (MEIRELES, 1977, p. 260).

Em janeiro de 1890, o governo central da República regulamentou a questão que provocara a crise no Maranhão: foi estabelecida a liberdade de culto, reconhecida a personalidade jurídica de todas as igrejas e confissões religiosas e garantida a posse de seus bens e templos. O governo também se prontificou a manter o pagamento das côngruas (pensão dos padres) e das cátedras (aulas) dos seminários, mas deixou ao arbítrio dos governos estaduais a decisão de manter ou não ministros de qualquer culto (MEIRELES, 1977). Como bem apontam os estudos,

[...] Carlos Roberto Jamil Cury (2001) [...] mostrou que o Decreto n. 119A/1890, redigido por Ry Barbosa, continha elementos de ambiguidade entre um Estado confessional e um Estado laico. Inspirado no federalismo norteamericano, ele deixava livres os governos estaduais para decidirem sobre a manutenção dos futuros ministros de determinado culto (seminaristas, por exemplo).

Mas, a promulgação da Constituição de 1891 eliminou a ambiguidade, ficando os governos federal e estaduais proibidos de subvencionar cultos ou igrejas, assim como interditados de estabelecer com eles relações de dependência. [...].

Em suma, a Constituição de 1891 declarou a Igreja Católica separada do Estado - ela passou, então, da esfera pública para a esfera privada. A União, os Estados e os Municípios foram proibidos de financiar qualquer tipo de atividade religiosa, bem como assumir importantes funções antes exclusivamente eclesiásticas, como o registro de nascimentos e de casamentos. (CUNHA, 2010, p. 194 e 195, grifos nossos).

Com isso, a historiografia eclesiástica comenta que, com a separação do Estado, não era a pobreza que chegava à Igreja maranhense, mas sim a miséria! (PACHÊCO, 1968). No campo da educação, convém recordar que, desde os princípios da República, tal como ocorria 
em todo o país, no Maranhão foi concedida liberdade para a iniciativa privada promover o ensino, o que favoreceu a Igreja Católica. Como preconiza a Lei n. 2/1892, que organiza o ensino nos municípios maranhenses, caberia às Câmaras Municipais a tarefa de regular o ensino primário, "mantendo e subvencionando escolas de qualquer grau, sem embargo das que forem fornecidas pelo Estado" (MARANHÃO, 1893). Ao se referir ao setor privado de ensino, essa lei determina: "É livre aos particulares abrir e reger escolas de qualquer grau ou natureza, sujeitas à inspeção oficial unicamente no que concerne à moralidade, higiene e estatística." Por sua vez, a Lei n. 56/1893, que organiza o ensino do estado, confirma a coexistência de escolas públicas e particulares: “Art. $2^{\circ}$. O ensino primário será dado: nas escolas primárias diretamente subvencionadas pelo Estado; nas escolas criadas e mantidas pelas municipalidades; nas escolas particulares" (MARANHÃO, s.d.). Doravante, o setor de ensino privado é incluído em todas as ações de supervisão, monitoria e fiscalização do Estado. O Decreto n. 1.390/1930, por exemplo, ao aprovar o regulamento do serviço de sanidade escolar, em seu art. $1^{\circ}$, preconiza que:

A inspeção médico escolar tem por fim zelar pela saúde dos alunos das escolas públicas e particulares e verificar se os estabelecimentos de ensino primário e secundário satisfazem as condições de higiene, do ponto de vista da localização, construção, ventilação, abastecimento d'água, e se o mobiliário e material escolar são adequados ao fim a que se destinam. (MARANHÃO, s.d.).

Nesse contexto jurídico-político, as iniciativas educacionais capuchinhas seriam muito bem-vindas: primeiro dos padres que se estabeleceram em São Luís em 1893 e de lá se expandiram pelo interior do estado, começando por Barra do Corda; depois das irmãs que chegaram a Barra do Corda em 1910 e seguiram fundando casas/escolas em várias cidades. Ainda que o Quadro 3, apresentado a seguir, seja incipiente e careça de mais levantamentos, são notáveis os dispositivos legais em prol da educação/evangelização dos frades e das freiras capuchinhos - o clássico estudo de Fernandes (2003), que cobre o período 1822-1929, no tópico “Auxílio ao Ensino Particular", menciona as escolas capuchinhas de Barra do Corda, Carolina, Grajaú, Imperatriz e Turiaçu. Evidentemente que as esferas de governo estadual e municipal não investiram somente na rede capuchinha, mas no Quadro 4, exposto a seguir, podem-se apreender indícios de que também eram favorecidos outros segmentos do grupo católico e mesmo de religiões cristãs e evangélicas. 
Quadro 3. Investimento do Estado na educação/evangelização capuchinha.

\begin{tabular}{|c|c|c|}
\hline LEGISLAÇÃO & $\begin{array}{c}\text { PRESCRIÇÃO } \\
\end{array}$ & GOVERNANTE \\
\hline Lei n. 574/1911 & $\begin{array}{l}\text { Autoriza o governo a nomear uma professora } \\
\text { normalista para o colégio das capuchinhas em } \\
\text { Barra do Corda. }\end{array}$ & $\begin{array}{l}\text { Governador Luiz A. } \\
\text { Domingues da Silva }\end{array}$ \\
\hline Lei n. 656/1914 & $\begin{array}{l}\text { Concede isenção de impostos de transmissão de } \\
\text { propriedade aos dois terrenos que frei Estevão de } \\
\text { Sexto adquirir nos arrebaldes da Barra do Corda, } \\
\text { para habitação e oficinas de menores desvalidos. }\end{array}$ & $\begin{array}{l}\text { Governador } \\
\text { Affonso Giffenig de } \\
\text { Mattos }\end{array}$ \\
\hline $\begin{array}{ll}\text { Lei } & \mathrm{n} . \\
1.172 / 1924 & \end{array}$ & $\begin{array}{l}\text { Autoriza o governo a auxiliar a missão dos } \\
\text { Capuchinhos Lombardos. }\end{array}$ & $\begin{array}{l}\text { Governador } \\
\text { Godofredo Mendes } \\
\text { Vianna }\end{array}$ \\
\hline $\begin{array}{l}\text { Decreto } \\
1.130 / 1927\end{array}$ & $\begin{array}{l}\text { Concede subvenções ao Colégio Osório, em } \\
\text { Guimarães, e à Escola Primária da Sagrada } \\
\text { Família, das irmãs capuchinhas, com sede em } \\
\text { Imperatriz. }\end{array}$ & $\begin{array}{lr}\text { Governador } & \text { J. } \\
\text { Magalhães } & \text { de } \\
\text { Almeida } & \end{array}$ \\
\hline $\begin{array}{l}\text { Decreto } \\
1.176 / 1928\end{array}$ & $\begin{array}{l}\text { Cria diversas escolas primárias e subvenciona } \\
\text { outras. } \\
\text { Subvencionados com } 600 \$ 000 \text { anuais o externato } \\
\text { Magalhães de Almeida, da vila de Porto Franco; a } \\
\text { Escola São José da Providência, da cidade de } \\
\text { Carolina, dos padres capuchinhos; o externato } \\
\text { Isaac Martins, da cidade de Balsas; e a escola } \\
\text { particular regida por dona Diva Coelho Rocha, da } \\
\text { vila do Riachão. }\end{array}$ & $\begin{array}{lr}\text { Governador } & \text { J. } \\
\text { Magalhães } & \text { de } \\
\text { Almeida } & \end{array}$ \\
\hline $\begin{array}{ll}\text { Decreto } & \mathrm{n} . \\
1.316 / 1930 & \end{array}$ & $\begin{array}{l}\text { Concede isenção de imposto de transmissão de } \\
\text { propriedade à Associação Educadora Italo- } \\
\text { Brasiliense, dos padres capuchinhos, com sede na } \\
\text { capital, sobre o terreno que adquirir na cidade de } \\
\text { Carolina para a construção de um prédio } \\
\text { destinado a um colégio naquela cidade. }\end{array}$ & $\begin{array}{l}\text { Governador José } \\
\text { Pires Sexto }\end{array}$ \\
\hline Lei n. $832 / 1952$ & $\begin{array}{l}\text { Outorga mandato à Escola Normal Regional de } \\
\text { Carolina. } \\
\text { Art. Único - Fica outorgado mandato à Escola } \\
\text { Normal Regional "Nossa Senhora da Piedade", de } \\
\text { Carolina, dirigida pelas Irmãs Terceiras } \\
\text { Capuchinhas, para ministrar o Curso de Ensino } \\
\text { Normal do } 1^{\circ} \text { ciclo. }\end{array}$ & $\begin{array}{l}\text { Governador } \\
\text { Eugênio Barros }\end{array}$ \\
\hline Lei n. 62/1955 & $\begin{array}{l}\text { Doação aos padres capuchinhos de um terreno } \\
\text { municipal ( } 100 \text { metros de frente e } 70 \text { de fundo) } \\
\text { para a construção da igreja Nossa de Fátima de } \\
\text { Imperatriz. }\end{array}$ & $\begin{array}{l}\text { Prefeito Simplício } \\
\text { Alves Moreira }\end{array}$ \\
\hline Lei n. 128/1959 & $\begin{array}{l}\text { Concessão de um auxílio de } 15 \text { mil cruzeiros para } \\
\text { construção do Salão São Francisco, de } \\
\text { propriedade das irmãs capuchinhas. }\end{array}$ & $\begin{array}{l}\text { Prefeito Raimundo } \\
\text { de Moraes Barros }\end{array}$ \\
\hline Lei n. 130/1959 & $\begin{array}{l}\text { O Poder Executivo ficou autorizado a } \\
\text { desapropriar três terrenos para a construção do } \\
\text { prédio da Escola Técnica Profissional a cargo da } \\
\text { Diocese de Carolina, representada pelos frades } \\
\text { capuchinhos. }\end{array}$ & $\begin{array}{l}\text { Prefeito Raimundo } \\
\text { de Moraes Barros }\end{array}$ \\
\hline
\end{tabular}


Fonte: MARANHÃO, 1914, 1915, 1925, 1928, 1929, 1952, s.d.; IMPERATRIZ, 1950-1959. ${ }^{10}$

Quadro 4. Investimento do Estado na educação/evangelização religiosa

\begin{tabular}{|c|c|c|}
\hline LEGISLAÇÃO & PRESCRIÇÃO & GOVERNANTE \\
\hline Lei n. 1.109/1923 & $\begin{array}{l}\text { Autoriza a entrega, à Arquidiocese do } \\
\text { Maranhão, de uma casa de propriedade do } \\
\text { Estado, na Vila de São Bernardo. }\end{array}$ & $\begin{array}{l}\text { Governador Godofredo } \\
\text { Mendes Vianna }\end{array}$ \\
\hline Lei n. 1.172/1924 & $\begin{array}{l}\text { Isenta do imposto de transmissão de } \\
\text { propriedade a casa adquirida por Maranham } \\
\text { Christian Mission. }\end{array}$ & $\begin{array}{l}\text { Governador Godofredo } \\
\text { Mendes Vianna }\end{array}$ \\
\hline $\begin{array}{ll}\text { Decreto } & \mathrm{n} . \\
1.197 / 1928 & \end{array}$ & $\begin{array}{l}\text { Dispõe sobre a manutenção do Instituto Dom } \\
\text { Francisco de Paula, na cidade de Viana. }\end{array}$ & $\begin{array}{l}\text { Governador J. } \\
\text { Magalhães de Almeida }\end{array}$ \\
\hline Lei n. $842 / 1952$ & $\begin{array}{l}\text { Considera de utilidade pública a Escola } \\
\text { Paroquial São José de Guimarães. }\end{array}$ & $\begin{array}{l}\text { Governador Eugênio } \\
\text { Barros }\end{array}$ \\
\hline Lei n. 83/1956 & $\begin{array}{l}\text { Concede ao pastor Luiz Moreira um auxílio } \\
\text { de } 5 \text { mil cruzeiros para a construção da Igreja } \\
\text { Pentecostal. }\end{array}$ & $\begin{array}{l}\text { Prefeito Antenor } \\
\text { Fontenele Bastos }\end{array}$ \\
\hline Lei n. 127/1959 & $\begin{array}{l}\text { Concede uma subvenção de seis mil cruzeiros } \\
\text { para a Escola de Alfabetização da Assembleia } \\
\text { de Deus. }\end{array}$ & $\begin{array}{l}\text { Prefeito Raimundo de } \\
\text { Moraes Barros }\end{array}$ \\
\hline
\end{tabular}

Fonte: MARANHÃO, 1924, 1925, 1929, 1952; IMPERATRIZ, 1950-1959.

É como diz Soares (2016, p. 47-48) ao estudar o Ginásio Pinheirense, na Baixada Maranhense, fundado pelos Missionários do Sagrado Coração nos anos 1950:

Deve-se ter em mente que em nível nacional a relação Estado-Igreja era de parceria e colaboração em prol do "bem comum" 11 (BRASIL, 1946), com subvenção estatal para as atividades assistenciais ligadas à Igreja. Em Pinheiro, essa parceria se fez presente por meio da aliança entre o grupo religioso liderado por dom Afonso Ungarelli [missionário do Sagrado Coração] e o grupo político PDS-PTB, liderado por Elisabetho Barbosa de Carvalho.

[...] Eles colaboraram nos trâmites de processos de autorização e reconhecimento institucionais, nomeações e subvenções federais em nome de dom Afonso Maria Ungareelli, para as realizações assistenciais e educativas da Ação Social da Prelazia de Pinheiro.

${ }^{10}$ Selecionamos a legislação a partir de 1910 porque esse ano marca a inserção da Congregação das Irmãs Missionárias Capuchinhas no Maranhão. Antes disso, o Estado investiu em outros projetos e trabalhos dos padres capuchinhos no Maranhão, tais como a Catequese e Civilização de Índios, mas é tema de outra pesquisa em curso.

${ }^{11}$ Já no início do governo Getúlio Vargas, o Decreto n. 19.941/1931vedava aos governos federal, estaduais e municipais terem relação de aliança com qualquer culto ou igreja, no entanto, "sem prejuízo da colaboração recíproca em prol do interesse coletivo" (CUNHA, 2010, p. 198). 
Embora a relação Estado-Igreja tenha sido pautada muitas vezes pela "parceria e colaboração", tensões e controvérsias também faziam parte do inusitado cotidiano missionário. É o que se pode verificar em um documento intitulado "Histórico", que é na verdade uma carta dos capuchinhos de São Luís, datada em 7 de agosto de 1934, dirigida ao governo do estado. Essa carta relata um fato no mínimo curioso, que ocorreu na cidade de Barra do Corda, em 1932, durante a visita de Luiz Gonzaga Roland (inspetor regional de ensino) ao Colégio de São José da Providência, dirigido pelas irmãs capuchinhas e mantido pela Associação Educadora Italo-Brasiliense (como se disse anteriormente, mantenedora dos trabalhos socioeducativos da rede capuchinha, criada em 1912).

Como era de praxe, o inspetor convidou os alunos do colégio, acompanhados de suas irmãs-professoras, para realizarem os exames escolares que foram ministrados no grupo escolar da cidade. Diz o documento: “O procedimento do senhor Roland, porém, para com os alunos do mencionado Colégio, foi tal de merecer censura por parte dos Padres, Irmãs e mais assistentes que lá se achavam [...]. As Irmãs Religiosas, nessa ocasião, passaram por vários vexames.” (ORDEM DOS FRADES MENORES CAPUCHINHOS, 1934).

No ano seguinte, o inspetor Roland convidou novamente alunos e irmãs para os exames escolares, mas a diretora do colégio, recordando os acontecimentos do ano anterior e receando passar por alguma humilhação, se justificou dizendo que "não podia atendê-lo e nem sequer licença tinha dos seus superiores para lá ir" (ORDEM DOS FRADES MENORES CAPUCHINHOS, 1934). Certamente para punir a recusa da freira que, diga-se de passagem, foi muito estratégica (!), Roland teria registrado a ocorrência em seu relatório. Pode-se supor que estava instaurada uma controvérsia com os capuchinhos.

O Sr. Luiz Gonzaga Roland pois em seu relatório apresentado à Diretoria Geral de Instrução Pública deu uma informação que depõe contra nós Religiosos Capuchinhos Lombardos residentes nesta cidade [São Luís], como insinuadores ao desrespeito às disposições legais, quando de todos somos muito bem conhecidos e estimados, graças a Deus, como dignos e respeitosos para com toda Autoridade Competente e seus dignos Auxiliares, de modo a merecer sempre, até agora, elogiosas referências. Foi em base a isto e aos muitos trabalhos e serviços em prol especialmente da mocidade e juventude brasileira, que os respectivos Governos nos ofereceram e ainda nos dispensam um auxílio mensal de 50:000 para cada Colégio que temos no Interior do Estado, além de material escolar que a Diretoria Geral da Instrução Pública anualmente nos dá. (ORDEM DOS FRADES MENORES CAPUCHINHOS, 1934, grifo nosso). 
Os capuchinhos - e, na esteira deles, as freiras capuchinhas - sabiam que ocupavam um lugar próprio na sociedade maranhense (nos termos certeausianos), uma vez que eram detentores de relevante capital cultural e social (nos termos bourdieusianos), a ponto de lhes permitir construir uma narrativa que dá a entender que o Estado reconhecia a utilidade social do trabalho religioso e, consequentemente, subsidiava a Ordem e a Congregação capuchinhas. Mas havia ainda uma injustiça a se reparar em nome do "amor à verdade": em 1934, na referida carta, eles solicitam à "Autoridade competente que se digne mandar cassar ou retirar aquela nota falsa e injuriosa que o Sr. Roland lançou em seu relatório" (ORDEM DOS FRADES MENORES CAPUCHINHOS, 1934) - surpreende que, apesar de minuciosa varredura, tal relatório não foi localizado no arquivo público do Maranhão! De que qualquer forma, a narrativa dos capuchinhos faz pensar na visão de sociedade dos religiosos, autoposicionados no seu centro, mas também revela eventuais atitudes autocráticas de certas autoridades públicas.

\section{Observações finais}

Com base neste estudo, podem-se inferir pistas para o que parece ser uma estratégia habitual das ordens, congregações e demais grupos religiosos que se dedicaram ao campo educacional no Brasil republicano: além de seus esforços para manterem ativas suas instituições educativas a partir de diversos meios (campanhas, arrecadações, mensalidades etc.), parece ser comum se desenvolverem por meio de alianças com políticos e/ou pessoas da elite local. Para além da rede capuchinha no Maranhão, as Irmãzinhas da Imaculada Conceição, congregação fundada por jesuítas italianos e moças imigrantes de Santa Catarina, se expandiram e se afirmaram em São Paulo, no início do século XX, a partir do contato e da articulação com políticos e membros da elite paulista, que financiaram sua viagem de Nova Trento (SC) para a cidade paulistana, providenciaram sua instalação no bairro Ipiranga para dirigirem um asilo de meninas negras e, com o tempo, doaram os terrenos onde elas já tinham feito benfeitorias e construído sua Casa Geral, um noviciado e um colégio feminino particular anexo ao asilo. Isso lhes permitiu, aliás, prescindir do apoio financeiro dessas mesmas elites e enraizar-se em São Paulo (CUSTÓDIO, 2014a).

Seja como for, a marca da ambiguidade na relação Estado-Igreja no Brasil parece muito forte. De fato, como ocorreu no Maranhão e provavelmente em outros lugares não cobertos por esta pesquisa, pode-se reconhecer a fragilidade dos governos que, por não conseguirem atender à demanda de escolas públicas, recorreram por vezes ao patrocínio da 
rede privada de ensino na tentativa de driblar o baixo número de instituições escolares e reduzir a alta taxa de analfabetismo. Há de se considerar, por outro lado, que uma das consequências dessa ambiguidade é a influência que um segmento exerceu sobre o outro, ou seja, o ponto em que a educação maranhense modificou-se pela presença da Igreja, ao passo que a Igreja empenhou-se na formação de cidadãos para além da religiosidade.

\section{Referências}

ARQUIVO HISTÓRICO DA PROVÍNCIA NOSSA SENHORA DO CARMO. São Luís do Maranhão. Fotos históricas.

ARQUIVO HISTÓRICO DA PROVÍNCIA NOSSA SENHORA DO CARMO. São Luís do Maranhão. Pastas e cartas avulsas de Frei Osvaldo Coronini. Manuscrito e Datilografado.

ASSOCIAÇÃO EDUCADORA ITALO-BRASILIENSE. Acta da sessão inaugural. São Luís, 1912. Mimeografado.

AZANHA, J. M. P. Planos e políticas de educação no Brasil: alguns pontos para reflexão. In: MENESES, J. G. de C et al. Educação básica: políticas, legislação e gestão. São Paulo: Pioneira Thomson Learning, 2004. p. 68-88.

CASTILHO, U. M. IMC. Irmãs Missionárias Capuchinhas: uma história de amor (feita de luzes e sombras) 1904-2004. Fortaleza: Congregação das Irmãs Capuchinhas, 2004.

CONGREGAÇÃO DAS IRMÃS MISSIONÁRIAS CAPUCHINHAS. Subsídios históricos. Fortaleza, 1976. Mimeografado.

CONGREGAÇÃO DAS IRMÃS MISSIONÁRIAS CAPUCHINHAS. Revista do centenário das IMC. Fortaleza, 2004.

CRUZ, M. dos S. Ampliação e modernização do sistema de ensino primário do interior do Maranhão. In: CONGRESSO BRASILEIRO DE HISTÓRIA DA EDUCAÇÃO, 7, 2013, Cuiabá. Anais... Cuiabá: UFMT, 2013. p. 1-15.

CUNHA, L. A. Confessionalismo versus laicidade no ensino público. In: SAVIANI, D. (Org.). Estado e políticas educacionais na história da educação brasileira. Vitória: EDUFES, 2010. p. 187-215. (Coleção horizontes da pesquisa em história da educação no Brasil, 2).

CURY, C. R. J. Cidadania republicana e educação: governo provisório do Mal. Deodoro e Congresso Constituinte de 1890-1891. Rio de Janeiro: DP\&A, 2001.

CUSTÓDIO, M. A. C. A invenção do cotidiano feminino: formação e trajetória de uma congregação católica. São Paulo: Annablume; Fapesp, 2014a. 
CUSTÓDIO, M. A. C. Da constituição de uma congregação feminina nordestina: análise de uma possível consequência sociorreligiosa da Rebelião do Alto Alegre - Maranhão. International Studies on Law and Education, São Paulo, n. 16, p. 63-76, jan./abr. 2014b.

CUSTÓDIO, M. A. C. Gênese de uma escola católica e estratégias femininas no Maranhão novecentista. Cadernos de Pesquisa, São Paulo, v. 45, n. 155, p. 178-198, jan./mar. 2015.

CUSTÓDIO, M. A. C.; CARDOSO, J. C. da S. Frei Osvaldo Coronini e a expansão da escolarização no Maranhão. Revista Internacional d'Humanitats, São Paulo, n. 40, p. 6980, maio/ago. 2017.

GINZBURG, C. Folklore, magia, religione. In: ROMANO, R.; VIVANTI, C. Storia d'Italia. Dalla caduta dell'Impero romano al secolo XVIII. Torino: Einaudi, 1972. v. 1. p. 1-77.

HILSDORF, M. L. S. História da educação brasileira: leituras. São Paulo: Pioneira Thomson Learning, 2005.

IBGE - Instituto Brasileiro de Geografia e Estatística. Síntese de indicadores sociais: uma análise das condições de vida da população brasileira. Rio de Janeiro: Ministério do Planejamento, Orçamento e Gestão IBGE, 2015. (Estudos \& Pesquisas, 35).

IMPERATRIZ. Prefeitura Municipal. Livro de transcrição: Leis, Decretos, Portarias e Ofícios (1932-1936). Cópia manuscrita.

IMPERATRIZ. Prefeitura Municipal. Livro de transcrição: Leis, Decretos, Portarias e Ofícios (1950-1959). Cópia manuscrita.

LEONARDI, P. Além dos espelhos: memórias, imagens e trabalhos de duas congregações católicas. São Paulo: Paulinas, 2010.

MARANHÃO. Collecção de Decretos, Leis e Resoluções do Governo do Estado do Maranhão de 22 de Novembro de 1889 a 31 de Dezembro de 1892. Maranhão, 1893.

MARANHÃO. Collecção das Leis do Governo do Estado do Maranhão dos annos de 1892 e 1893. [s.d.].

MARANHÃ̃. Collecção das Leis e Resolução do Congresso, Decretos e Decisões do Estado do Maranhão de 1911. Imprensa Official, 1914.

MARANHÃO. Colleção das eis do Congresso, Decretos e Regulamentos do Governo do Estado do Maranhão do Anno de 1914. Imprensa Official, 1915.

MARANHÃ̃. Collecção das Leis e Decretos do Estado do Maranhão do Anno de 1918. Imprensa Official, 1918.

MARANHÃ̃. Collecção das Leis e Decretos do Estado do Maranhão do Anno de 1923. Imprensa Official, 1924. 
MARANHÃO. Collecção das Leis e Decretos do Estado do Maranhão do Anno de 1924. Imprensa Official, 1925.

MARANHÃ̃. Collecção das Leis e Decretos do Estado do Maranhão do Anno de 1927. Imprensa Oficial, 1928.

MARANHÃO. Collecção das Leis e Decretos do Estado do Maranhão do Anno de 1928. Imprensa Oficial, 1929.

MARANHÃO. Collecção de Decretos do Anno de 1930. Imprensa Official. [s.d.].

MARANHÃO. Coleção de Leis e Decretos de Janeiro a Dezembro de 1948. Maranhão, 1948.

MARANHÃ̃. Coleção de Leis e Decretos de Janeiro a Dezembro de 1952. Maranhão, 1952.

MARANHÃO. Coleção de Leis e Decretos de Janeiro a Dezembro de 1953. Maranhão, 1953.

MEIRELES, M. M. História da Arquidiocese de São Luís do Maranhão. São Luís: Universidade Federal do Maranhão, 1977.

NAGLE, J. A educação na Primeira República. In: FAUSTO, B. (Org.). História geral da civilização brasileira. 8. ed. Rio de Janeiro: Bertrand Brasil, 2006. t. 3. v. 2. p. 283-318.

NEMBRO, M. OFMC. I cappuccini nel Brasile: Missione e Custodia del Maranhão (18921956). Milano: Centro Studi Cappuccini Lombardi, 1957.

ORDEM DOS FRADES MENORES CAPUCHINHOS. Histórico. São Luís, 1934. Datilografado.

ORDEM DOS FRADES CAPUCHINHOS MENORES. Arquivo Histórico da Província Nossa Senhora do Carmo, São Luís do Maranhão. Relatórios do Movimento Religioso das Paróquias. Manuscrito e Datilografado.

PACHÊCO, F. C. História Eclesiástica do Maranhão. São Luís: Departamento de Cultura do Estado, 1968.

QUEIROZ, C. Religião e política no ensino: congregações católicas europeias supriram demanda por escolas no Brasil entre o fim do século XIX e a segunda metade do XX. Pesquisa FAPESP, São Paulo, n. 243, p. 84-87, maio 2016.

RORIZ, J. CSSR. A educação nas constituições brasileiras de 1891, 1934, 1937, 1946. São Paulo: Empresa Gráfica da Revista dos Tribunais Ltda, 1951.

SAVIANI, D. Da nova LDB ao FUNDEB. 4. ed. rev. Campinas: Autores Associados, 2011. 
SILVA, D. R. da. A institucionalização dos grupos escolares no Maranhão (1903-1920). São Luís: Editora UEMA, 2015.

SILVA, J. N. O.; CASTRO, M. P. de. Escola Santa Teresinha 80 anos educando vidas. Imperatriz: Ética, 2004.

SOARES, A. L. A. Ginásio Pinheirense: criação e inserção no contexto sociocultural da Baixada e Litoral Ocidental Maranhense (1953-1963). Dissertação (Mestrado em Educação) Faculdade de Educação, Universidade de São Paulo, São Paulo, 2016. 